\title{
Analysis of in-situ vibration monitoring for end-point detection of CMP
} planarization processes

Dale L. Hetherington, David J. Stein, James P. Lauffer, Edward E. Wyckoff, and David 4418 hjngledecker
Sandia National Laboratories, MS 1084, Albuquerque, NM 87185
ABSTRACT

This paper details the analysis of vibration monitoring for end-point control in oxide CMP processes. Two piezoelectric accelerometers were integrated onto the backside of a stainless steel polishing head of an IPEC 472 polisher. One sensor was placed perpendicular to the carrier plate (vertical) and the other parallel to the plate (horizontal). Wafers patterned with metal and coated with oxide material were polished at different speeds and pressures. Our results show that it is possible to sense a change in the vibration signal over time during planarization of oxide material on patterned wafers. The horizontal accelerometer showed more sensitivity to change in vibration amplitude compared to the vertical accelerometer for a given polish condition. At low carrier and platen rotation rates, the change in vibration signal over time at fixed frequencies decreased approximately $1 / 2-1$ order of magnitude (over the 2 to $10 \mathrm{psi}$ polish pressure ranges). At high rotation speeds, the vibration signal remained essentially constant indicating that other factors dominated the vibration signal. These results show that while it is possible to sense changes in acceleration during polishing, more robust hardware and signal processing algorithms are required to ensure its use over a wide range of process conditions.

Keywords: chemical mechanical polishing, CMP, planarization, endpoint, vibration

\section{INTRODUCTION}

Establishing a solid end-point method for chemical-mechanical polishing (CMP) processes leads to improved manufacturability, increased wafer yield, and higher throughput. Several methods have been investigated including optical, thermal (pad temperature), friction (torque motor current), electrochemical, and acoustic (vibration). ${ }^{1-5}$ A number of patents have been issued related to these techniques. ${ }^{6}$ All of these methods face a similar set of challenges: (1) incompatible CMP equipment designs, (2) limitations on sensor integration into rotating polisher systems, and (3) low signal-to-noise ratios in polishing environments. End-point techniques require robust hardware designs and software algorithms that can be applied across a broad range of process conditions including patterned wafer types and CMP consumables.

CMP processes described here are categorized into dielectric, metal, polysilicon, and shallow trench isolation (STI). Most of the in-situ end-point techniques have been performed on metal CMP where the end of the process involves a transition from the metal film to an oxide layer which acts as a "polish stop". Figure 1(a) shows a conventional metal CMP process illustrating the start and stop process conditions. End-point is detected when the polishing process transitions through the metal and liner materials, stopping on the insulating layer. Temperature and torque motor current sensing have worked successfully in tungsten metal CMP processes. ${ }^{7}$
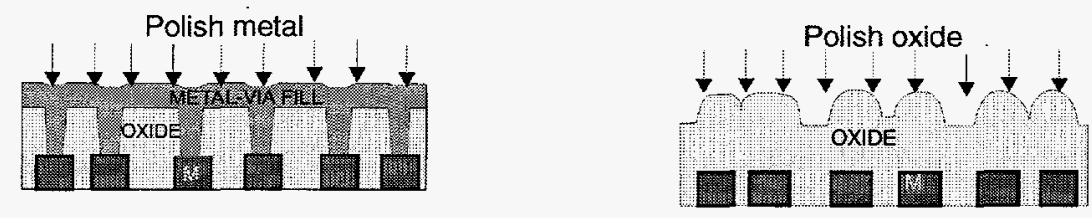

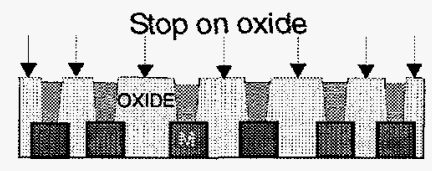

(a)

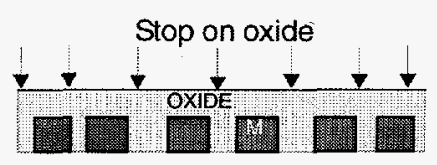

(b)

Figure 1. Process scenarios for (a) metal CMP where polishing starts on metal film and stops on low polish rate oxide material, and (b) dielectric CMP where only one layer is polished.

For further author information -

D.L.H. (correspondence): email: dihethe@sandia.gov

Telephone: 505-844-6155; Fax: 505-844-2991

To be presented at SPIE Symposium on Microelectronic Manufacturing Technologies- May 19, 1999 


\section{DISCLAIMER}

This report was prepared as an account of work sponsored by an agency of the United States Government. Neither the United States Government nor any agency thereof, nor any of their employees, make any warranty, express or implied, or assumes any legal liability or responsibility for the accuracy, completeness, or usefulness of any information, apparatus, product, or process disclosed, or represents that its use would not infringe privately owned rights. Reference herein to any specific commercial product, process, or service by trade name, trademark, manufacturer, or otherwise does not necessarily constitute or imply its endorsement, recommendation, or favoring by the United States Government or any agency thereof. The views and opinions of authors expressed herein do not necessarily state or reflect those of the United States Government or any agency thereof. 


\section{DISCLAIMER}

Portions of this document may be illegible in electronic image products. Images are produced from the best available original document. 
The most difficult scenario for CMP end-point detection is continuous layer polishing. An example is the back-end-of-line dielectric CMP process shown in Figure 1(b). The polishing starts and stops on the same layer. This type of process usually employs an empirically determined polish time.

One CMP monitoring technique that has been investigated as a method of planarization end-point is vibration sensing. ${ }^{1,-12}$ A vibration signal may be detected on the back-side of the wafer carrier during polishing. As the topography of the dielectric material undergoing polishing reduces, the vibration signal may decrease. Thus, a planarization end-point can be obtained by determining the time at which the vibration signal drops to a minimum. The problems with this technique are: (1) specific carrier designs may not allow for efficient coupling of the vibration excitation signal (from the wafer patterns) to the sensor, (2) high performance (high sensitivity, low noise, and wide bandwidth) vibration sensors are required, and (3) sensor data acquisition and signal processing onto and off of a rotating polishing head is difficult.

Optical techniques are also being investigated. ${ }^{13}$ For this technique, the signal is measured directly on the front-side of the wafer as it passes through an optical thickness measurement window typically embedded into the polishing pad. Optical endpoint becomes more challenging as the number of mask levels increases due to scattering from underlying patterns. This method is also tasked with measuring a rotating wafer in a wet slurry environment.

The purpose of this study is to assess the feasibility of in-situ vibration monitoring for a conventional type dielectric CMP process. The polishing system studied here is an IPEC 472 machine incorporating a standard stainless steel flat carrier, an example of which is shown in Figure 2. The effects of speed and pressure on vibration sensing using accelerometers integrated into the back-side of the stainless-steel carrier are shown.

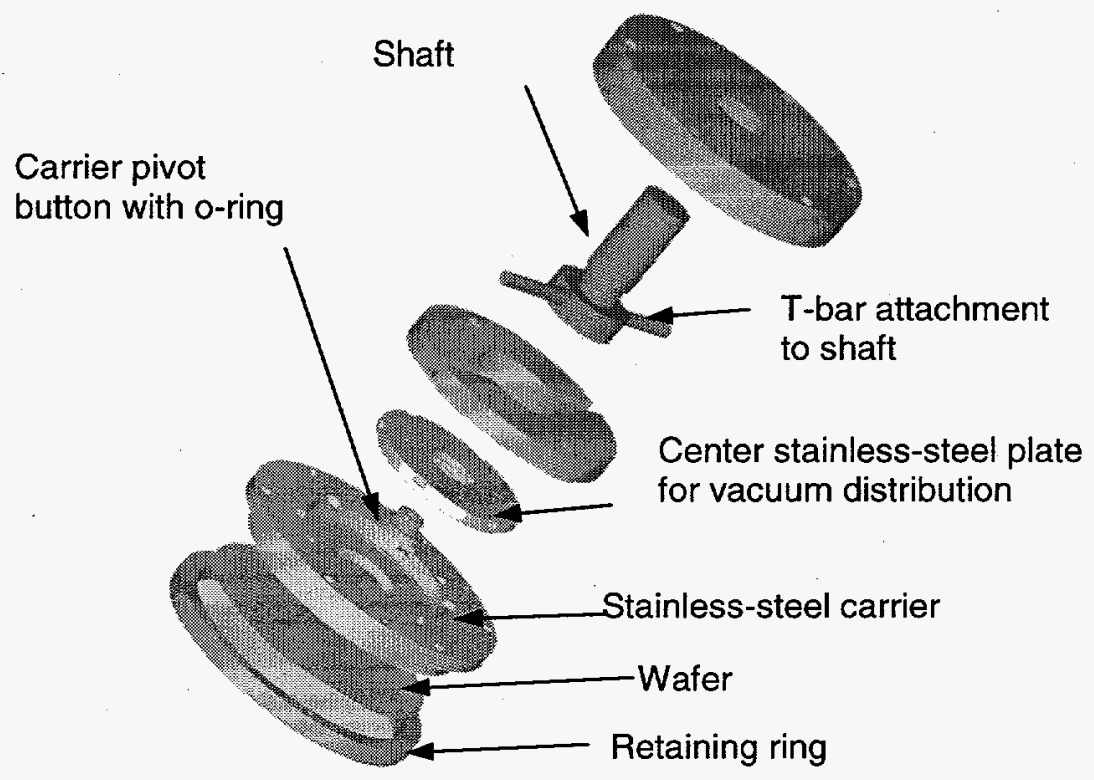

Figure 2. Schematic of the IPEC 472 polishing head. The wafer is mounted onto the carrier using a felt-like insert material that cushions the wafer during polish. The stainless-steel carrier pivots about the center shaft using a plastic button/rubber o-ring design. Pressure is applied to the shaft, which couples to the pivot button and the t-bar assembly.

\section{EXPERIMENTAL}

\subsection{Experimental modal analysis of the polishing head}

A vibration modal analysis was performed on the stainless-steel carrier to determine the resonating modes of the carrier. Figure 3 shows a plot of the frequency response function between the input force and the resulting acceleration. Two of the locations ( 1 and 2 ) were taken near the edge of the carrier to determine the flexing modes and any orthogonal mode pairs associated with the carrier, and a third location was taken on the back-side of the carrier on the vacuum distribution plate 
(Figure 2). The excitation force was an impulse obtained by tapping the carrier with a small hammer instrumented with a load cell. As shown in Figure 3, the resonant frequencies of the carrier occur at approximately $2.8 \mathrm{kHz}, 5.3 \mathrm{kHz}$, and $7 \mathrm{kHz}$. The location on the vacuum distribution plate also has two resonant peaks at frequencies of $4.5 \mathrm{kHz}$ and $8 \mathrm{kHz}$. Figure 4 shows a further analysis of the frequency response function for front-side and back-side responses to a driving-point located on the front-side. The vibration signal measured on the back-side due to a driving-point on the front-side is attenuated by an order of magnitude compared to the front-side response to the same impulse.

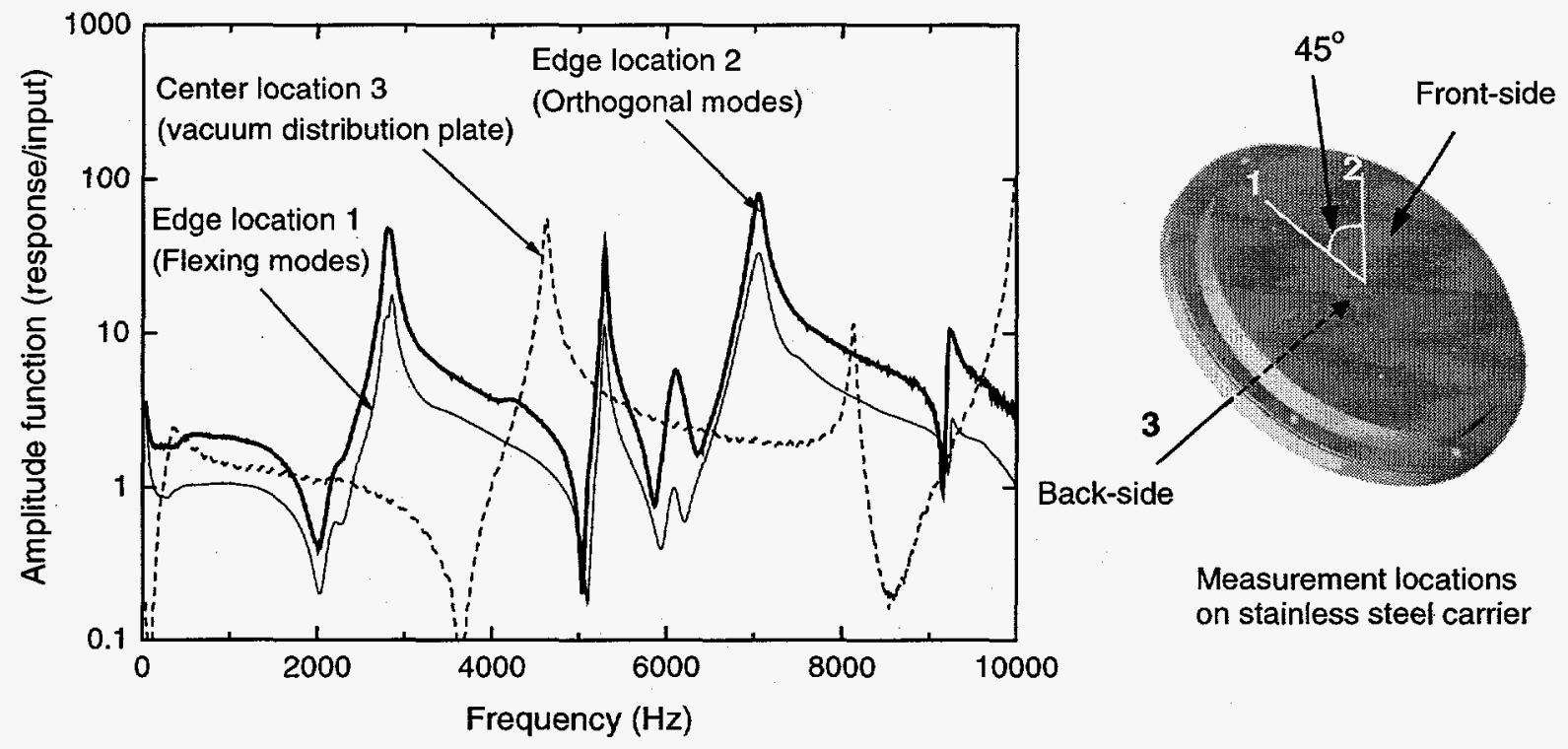

Figure 3. Plot of amplitude function (ratio of output/input) versus frequency for the IPEC 472 stainless steel carrier used in this study. The three locations are given on the schematic adjacent to the plot.

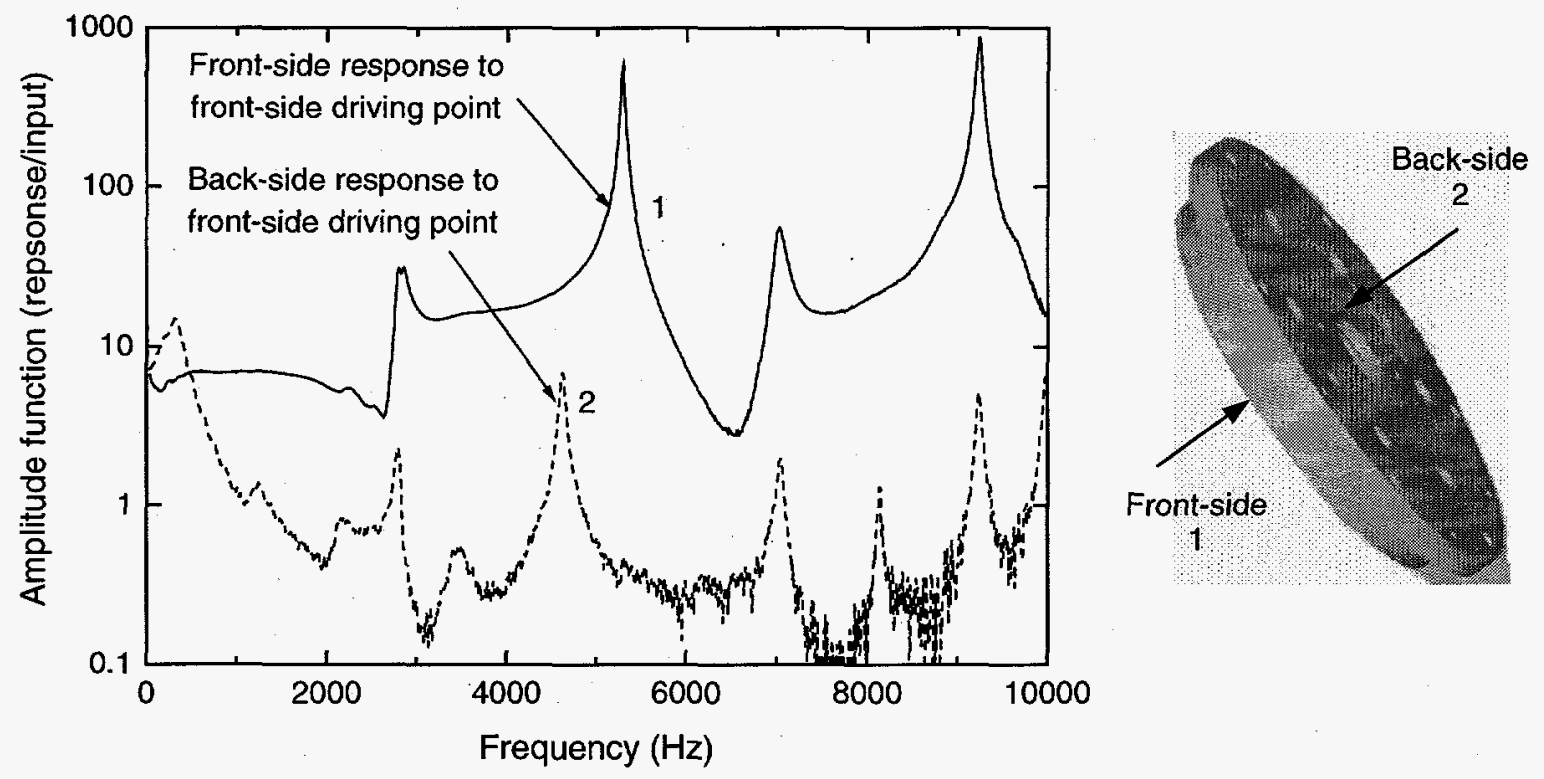

Figure 4. Plot of amplitude function (ratio of output/input) versus frequency for the center location front and back-side of the polishing head.

To be presented at SPIE Symposium on Microelectronic Manufacturing Technologies- May 19, 1999 
This reduction in response is due to the rubber o-ring that isolates the center vacuum plate from the bulk of the carrier assembly.

The results from the experimental modal analysis of the carrier suggest that the accelerometers should be located on the backside of the polishing head towards the edge of the carrier. Placement of the sensors on the vacuum distribution plate (see Figure 2) would produce an attenuated vibration signal from the wafer.

\subsection{Sensor integration}

Two accelerometers produced by Endevco Corp. (Model 7259A-500) were mounted on the backside of the flat, stainless steel wafer carrier approximately $25 \mathrm{~mm}$ from the edge. One sensor was placed parallel to the carrier base (horizontal) and the other perpendicular (vertical). Figure 5(a) shows an image of the location of the sensors with respect to the IPEC 472 polishing head.

A schematic diagram of the sensor system integrated onto the polisher is shown in Figure 5(b). Transmission of the sensor signals during polish was accomplished using an instrumentation slip-ring manufactured by Fabricast, Inc. Although a wireless transmission unit would potentially have lower noise, we chose a slip-ring approach for initial investigation due to ease of integration. To minimize the noise induced from the slip-ring, we custom built and installed directly onto the polishing head a circuit consisting of a constant current supply and a front-end ac amplifier for each sensor. The constant current supply biased the accelerometer at $4 \mathrm{~mA}$. The ac amplifier had a fixed amplitude gain of $40 \mathrm{~dB}$. Sensor signals below $100 \mathrm{~Hz}$ in frequency were pre-filtered out of the ac amplifier circuit. After amplification, the vibration signals were transmitted off of the polishing head through the slip-ring and ac coupled to a data acquisition system manufactured by National Instruments. Data were collected using a 12-bit resolution analog-to-digital conversion system sampling at 200,000 samples per second. The frequency spectrums were analyzed using standard Fourier transform (FFT) algorithms.

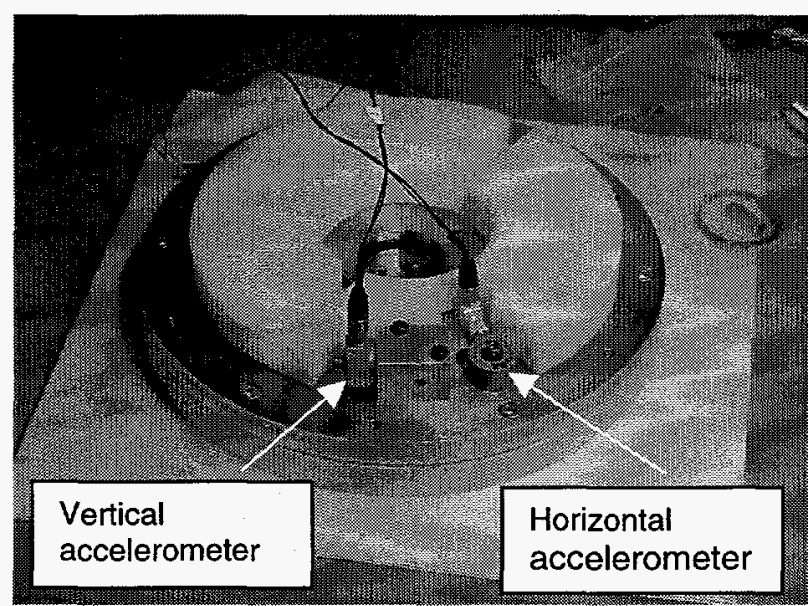

(a)

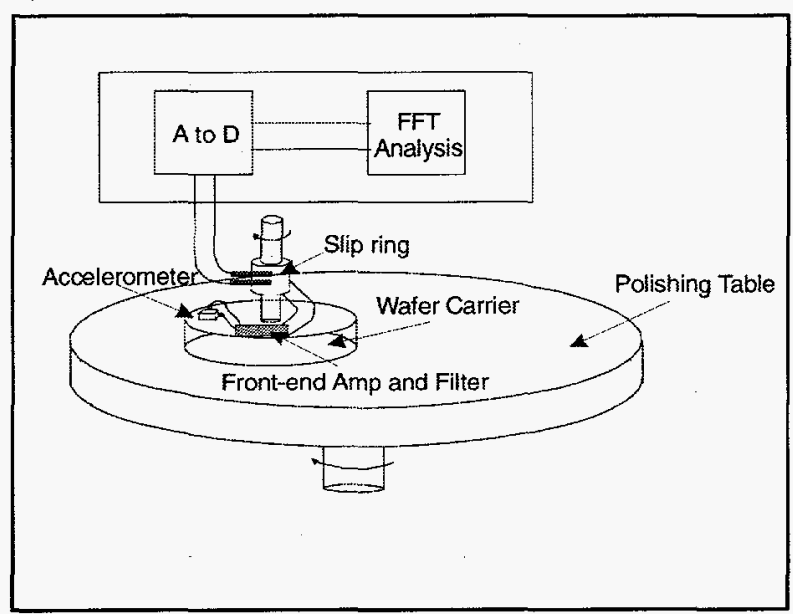

(b)

Figure 5. Vibration sensing system integrated into CMP (IPEC 472) polisher: (a) Photograph of modified polishing head showing location of vertical and horizontal accelerometers and (b) Schematic representation of sensor system integration.

Table 1 gives the accelerometer performance specifications used in this study. This particular piezoelectric accelerometer is a lead-zirconite crystal that produces charge corresponding to annular shear deformation. An internal hybrid signal conditioning circuit converts the charge to a low impedance output voltage. The ac output signal is superimposed onto an approximately $10 \mathrm{~V} \mathrm{dc}$ fixed bias point. The voltage sensitivity is $500 \mathrm{mV} / \mathrm{g}$ (without external amplification) and the lower limit of sensitivity is $100 \mu \mathrm{V} \mathrm{rms}(200 \mu \mathrm{g} \mathrm{rms})$. The voltage sensitivity of the vibration detection system including external gain from the ac amplifier is $50 \mathrm{~V} / \mathrm{g}$.

To be presented at SPIE Symposium on Microelectronic Manufacturing Technologies- May 19, 1999 


\begin{tabular}{|l|l|}
\hline \multicolumn{1}{|c|}{ Item } & Specification \\
\hline Voltage Sensitivity, $\pm 10 \%$ & $500 \mathrm{mV} / \mathrm{g}$ \\
\hline $\begin{array}{l}\text { Bandwidth } \\
\text { (amplitude response, } \pm 5 \%)\end{array}$ & $2 \mathrm{~Hz}-10 \mathrm{kHz}$ \\
\hline Residual Noise & $200 \mu \mathrm{g} \mathrm{rms}$ \\
\hline Range & $\pm 10 \mathrm{~g}$ \\
\hline Resonance Frequency & $45 \mathrm{kHz}$ \\
\hline Sensor Mass & $10.5 \mathrm{gm}$ \\
\hline
\end{tabular}

Table 1. Accelerometer specifications manufactured by Endevco Corp. (Model 7259A-500).

\subsection{Polishing experiments}

Standard consumables were utilized for all polishing experiments. The slurry type was a $\mathrm{KOH}$-based colloidal fumed silica manufactured by Cabot Corp. (SS-12). The polishing pad consisted of a 50 mil thick porous polyurethane pad stacked on top of a soft 50 mil thick foam pad manufactured by Rodel, Inc. (IC1400 K Groove). The insert material, which is placed between the wafer and stainless-steel carrier to provide cushioning, was a felt insert pad manufactured by Rodel, Inc. (R200 T3 Ultrathin).

In-situ pad conditioning using the APP1000 conditioning system on the IPEC 472 was performed on all polishing runs. The end effector was a 2-inch diameter nickel-diamond spiral disk (100 grit). The downforce applied to the end effector was $6 \mathrm{lbs}$ and the sweep rate was $34 \mathrm{~s}$ from the center of the pad to the edge. The slurry flow rate was kept constant throughout all experiments at $100 \mathrm{ml} / \mathrm{min}$.

Blanket $150 \mathrm{~mm}$ diameter silicon wafers coated with silicon dioxide material deposited by plasma enhanced chemical vapor deposition tetraethyl orthosilicate glass (PETEOS) were polished as a function of polish speed and pressure. Table 2 summarizes the removal rate data obtained on the four polish conditions.

Patterned wafers were fabricated using a short loop interconnect process flow that consisted of: (1) deposit $0.8 \mu \mathrm{m}$ thick PETEOS on bare silicon wafers, (2) sputter deposit Ti/Al/Cu $\mathrm{Cu}_{0.5} / \mathrm{TiN}$ metal film stack (total thickness $0.8 \mu \mathrm{m}$ ), (3) photopattern and etch the metal, and (4) deposit $2 \mu \mathrm{m}$ thick PETEOS film over the metal interconnect features. The patterns consisted of structures that varied in pitch between $1.4 \mu \mathrm{m}$ and $1 \mathrm{~mm}$ with a constant pattern density of $50 \%$. Polish times required to reach planarization for the different polish parameters were based on blanket removal rate data.

\begin{tabular}{|c|c|c|c|c|}
\hline Process & $\begin{array}{c}\text { Carrier } \\
\text { speed } \\
(\mathbf{r p m})\end{array}$ & $\begin{array}{c}\text { Platen } \\
\text { speed } \\
(\mathbf{r p m})\end{array}$ & $\begin{array}{c}\text { Carrier } \\
\text { pressure } \\
\text { (psi) }\end{array}$ & $\begin{array}{c}\text { Mean removal } \\
\text { rate } \\
(\mathbf{n m} / \mathbf{m i n})\end{array}$ \\
\hline 1 & 20 & 20 & 2 & 45 \\
\hline 2 & 20 & 20 & 10 & 254 \\
\hline 3 & 100 & 100 & 2 & 128 \\
\hline 4 & 100 & 100 & 10 & 815 \\
\hline
\end{tabular}

Table 2. Polish removal rate data on blanket wafers coated with PETEOS oxide material for various combinations of speed and pressure.

To be presented at SPIE Symposium on Microelectronic Manufacturing Technologies- May 19, 1999 


\subsection{Baseline system evaluation}

\section{RESULTS AND DISCUSSION}

The vibration amplitude signals were monitored for the no polish condition to obtain the lower noise limit of the system as a control compared to blanket wafer polishing. Figures 6 and 7 show the vibration intensity signal as a function of frequency for the vertical and horizontal output signals. The polishing parameters for the low-speed, low-pressure setting (process 1) and high-speed, high-pressure setting (process 4 ) are given in Table 2.

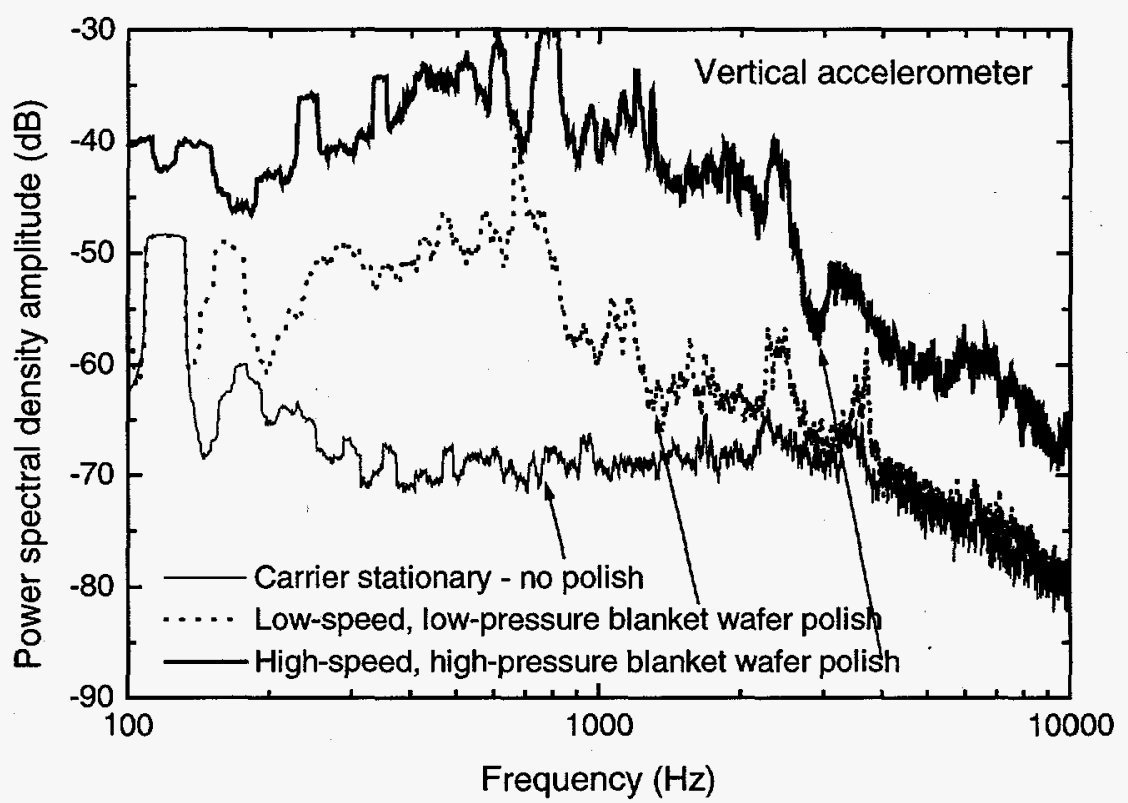

Figure 6. Power spectral density of vertical vibration signal versus frequency for blanket wafer polishing and no polish conditions.

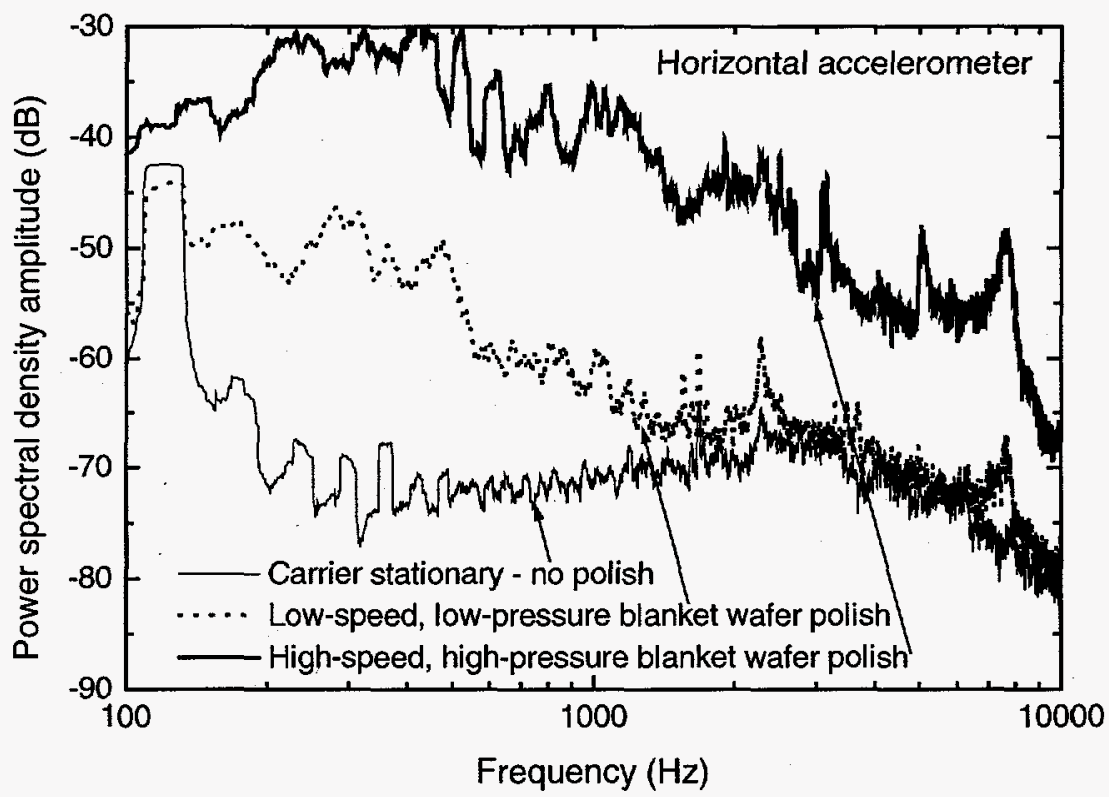

Figure 7. Power spectral density of horizontal vibration signal versus frequency for blanket wafer polishing and no polish conditions.

To be presented at SPIE Symposium on Microelectronic Manufacturing Technologies- May 19, 1999 
As shown in Figures 6 and 7, the power spectral density lower noise limit for no polish (no rotation) is flat at $-70 \mathrm{~dB}$ over the range of $200 \mathrm{~Hz}-2 \mathrm{kHz}$, well below the low-speed, low-pressure polish condition for the same frequency range. Beyond $1 \mathrm{kHz}$, the vibration response for low level polish conditions on a blanket wafer follows the no polish (no rotation) response. At higher polish rotation speeds and pressures on a blanket wafer, the power spectral density signal increases by $20 \mathrm{~dB}$ compared to the low level polish conditions.

It is useful to calculate the expected range of primary frequencies generated from periodic asperities of fixed dimension moving at a fixed velocity. Figure 8 shows a plot of the calculated asperity wave frequency versus pitch dimension for the case of low- and high-speed polish conditions. This graph provides an estimate of frequencies over which the wafer or pad asperity dimensions may generate a first order vibration mode. Based on this calculation, sub-micron interconnect dimensions are not likely to be detected directly using vibration monitoring during polish. However, pad asperity dimensions $(\sim 50 \mu \mathrm{m})$ or global chip-level features $(\sim 1-5 \mathrm{~mm})$ may be sensed using vibration measurements during polish.

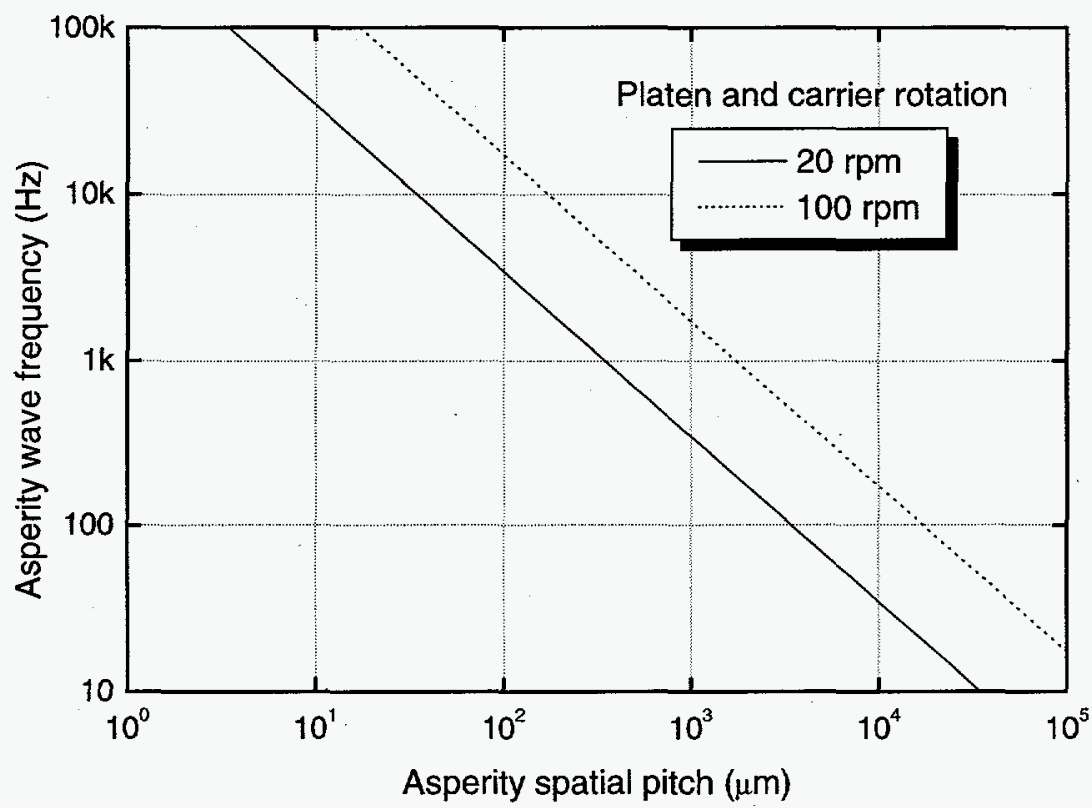

Figure 8. Calculation of asperity wave frequency versus pitch dimension for low and high-speed polish conditions.

\subsection{Planarization results}

Four process conditions were investigated on patterned wafers at the settings given in Table 2 . The polish times for each process were estimated from blanket wafer removal rates. Data were collected for both horizontal and vertical acceleration during polishing. The start data collection time was $20 \mathrm{~s}$ into the polish process. The end data collection time was within $5 \mathrm{~s}$ of the timed end polish cycle.

Figure 9 through 14 show the power spectral density amplitude response for each accelerometer at a particular CMP process condition for the start and end polish times. These data give an indication of whether the vibration signal attenuates over the entire polish cycle in the frequency range of $100 \mathrm{~Hz}$ to $10 \mathrm{kHz}$. Three points are observed from the data. First, the horizontal accelerometer shows a larger change in vibration amplitude attenuation from start to stop polish time over a wider range of frequencies than the vertical accelerometer for all process conditions. Second, increasing the speed of the platen and carrier from $20 \mathrm{rpm}$ to $100 \mathrm{rpm}$ minimizes the change in vibration signal (compare Figure 10 to Figure 14). Third, increasing the pressure for a given polish velocity produces a slightly larger change in vibration.

To be presented at SPIE Symposium on Microelectronic Manufacturing Technologies- May 19, 1999 


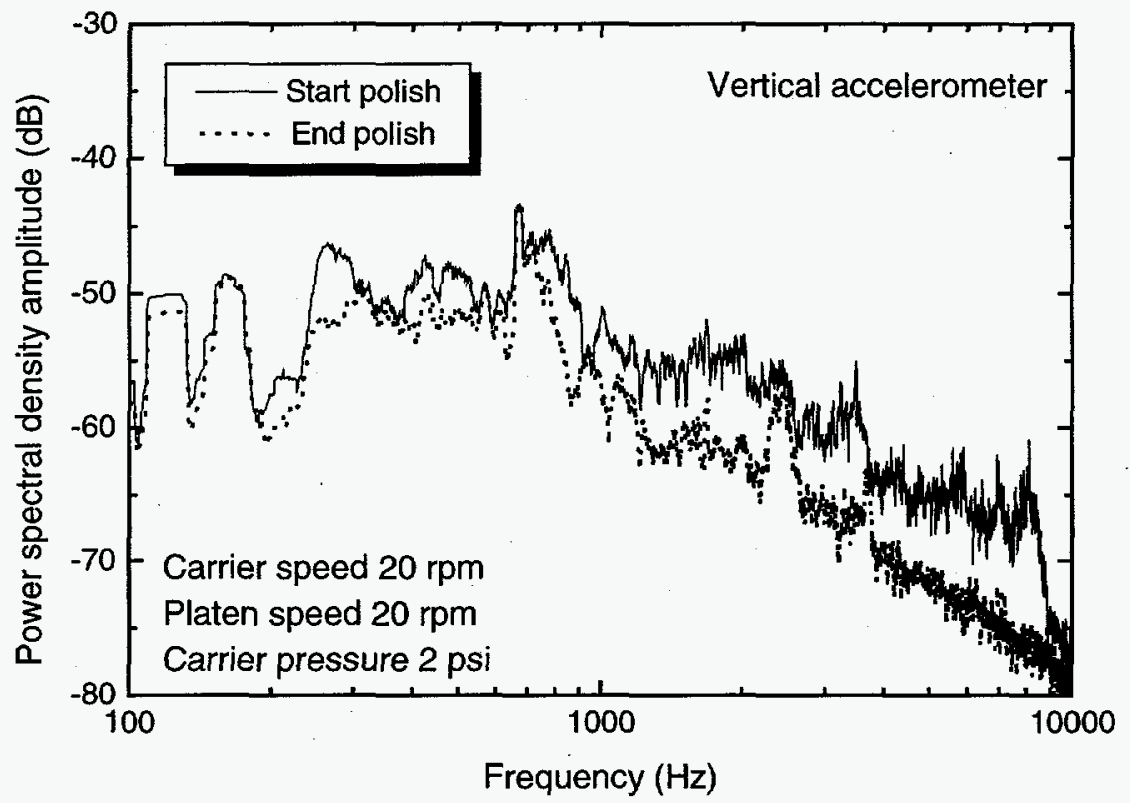

Figure 9. Power spectral density amplitude plot of the vertical accelerometer vibration amplitude signal monitored during the low-pressure, low-speed planarization process. Shown are the start and end polish times.

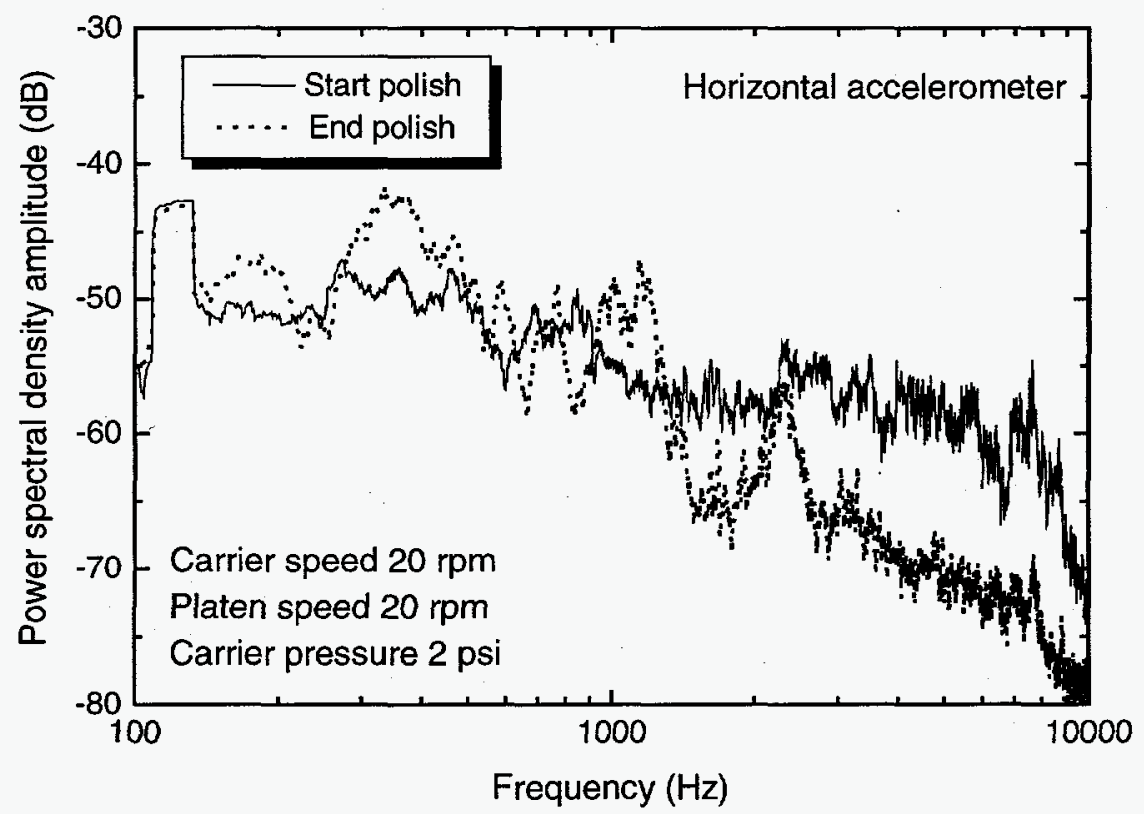

Figure 10. Power spectral density amplitude plot of the horizontal accelerometer vibration amplitude signal monitored during the low-pressure, low-speed planarization process. Shown are the start and end polish times.

To be presented at SPIE Symposium on Microelectronic Manufacturing Technologies- May 19, 1999 


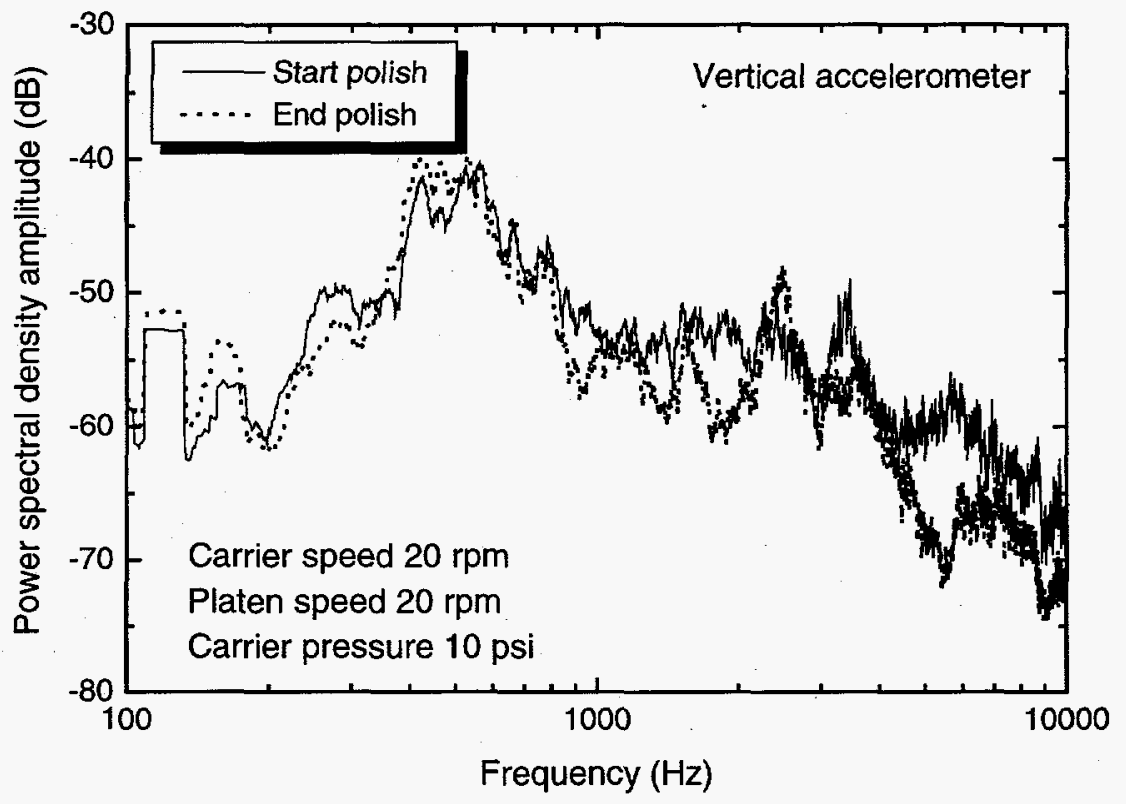

Figure 11. Power spectral density amplitude plot of the vertical accelerometer vibration amplitude signal monitored during the high-pressure, low-speed planarization process. Shown are the start and end polish times.

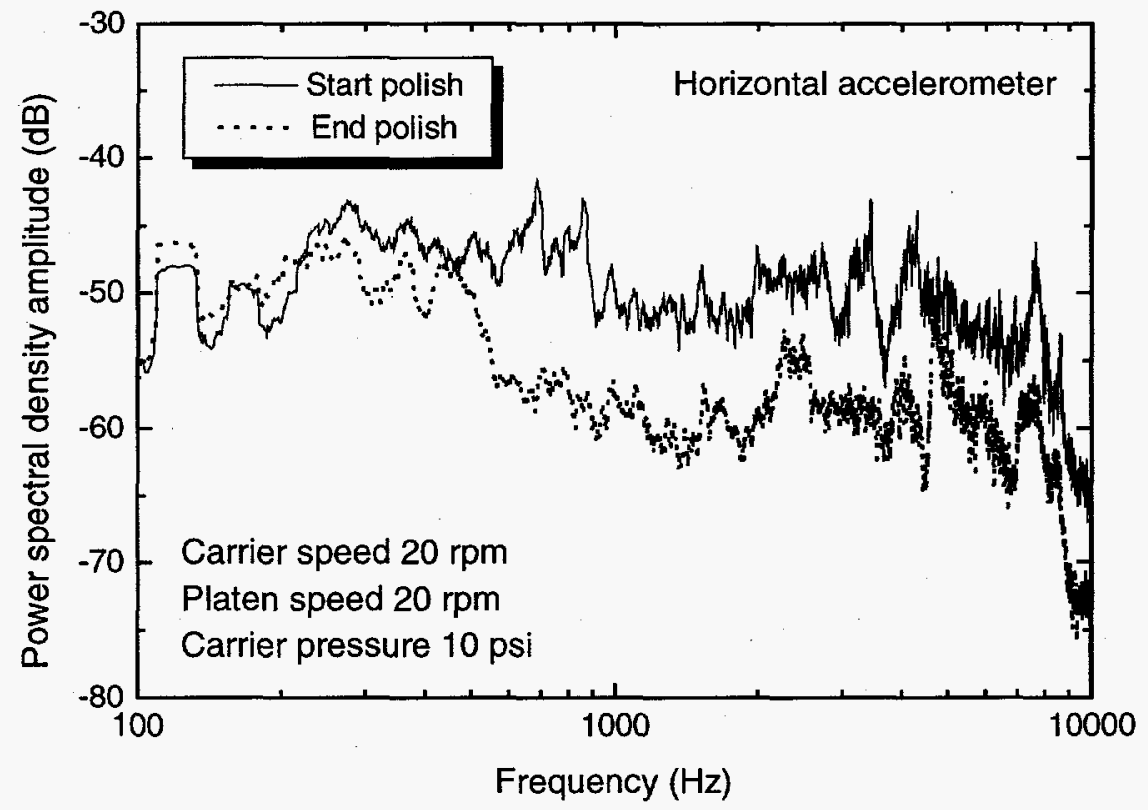

Figure 12. Power spectral density amplitude plot of the horizontal accelerometer vibration amplitude signal monitored during the high-pressure, low-speed planarization process. Shown are the start and end polish times.

To be presented at SPIE Symposium on Microelectronic Manufacturing Technologies- May 19, 1999 


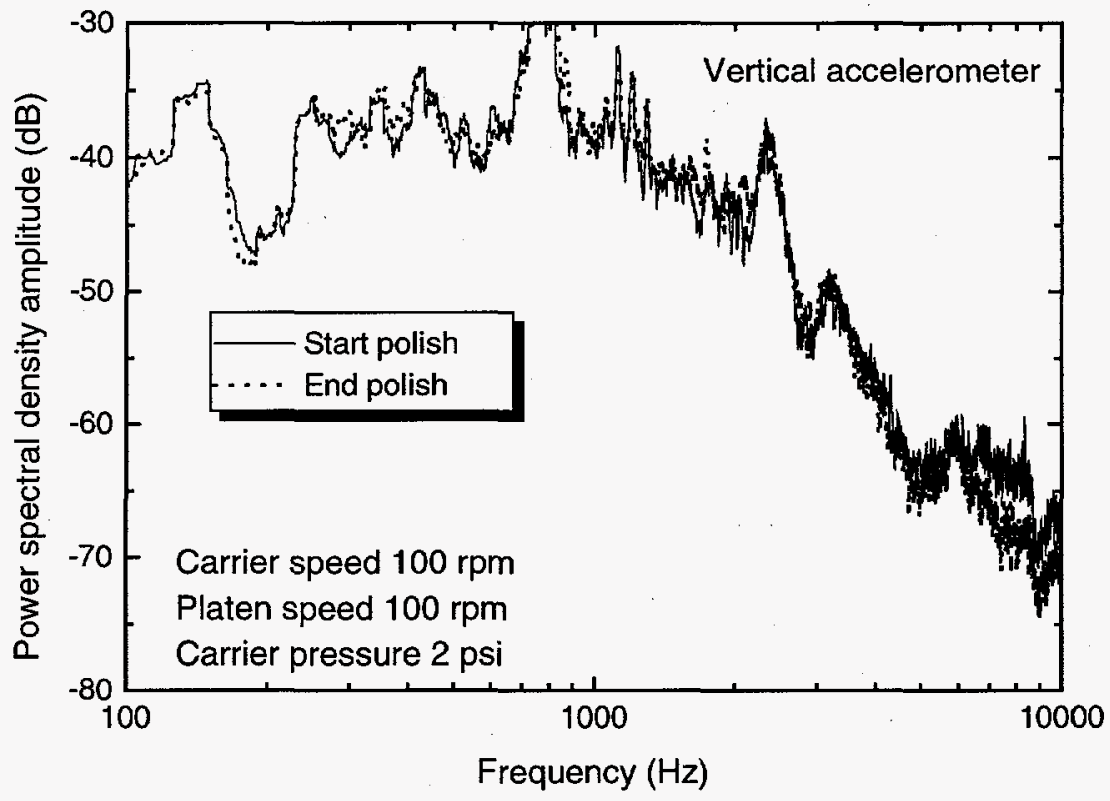

Figure 13. Power spectral density amplitude plot of the vertical accelerometer vibration amplitude signal monitored during the low-pressure, high-speed planarization process. Shown are the start and end polish times.

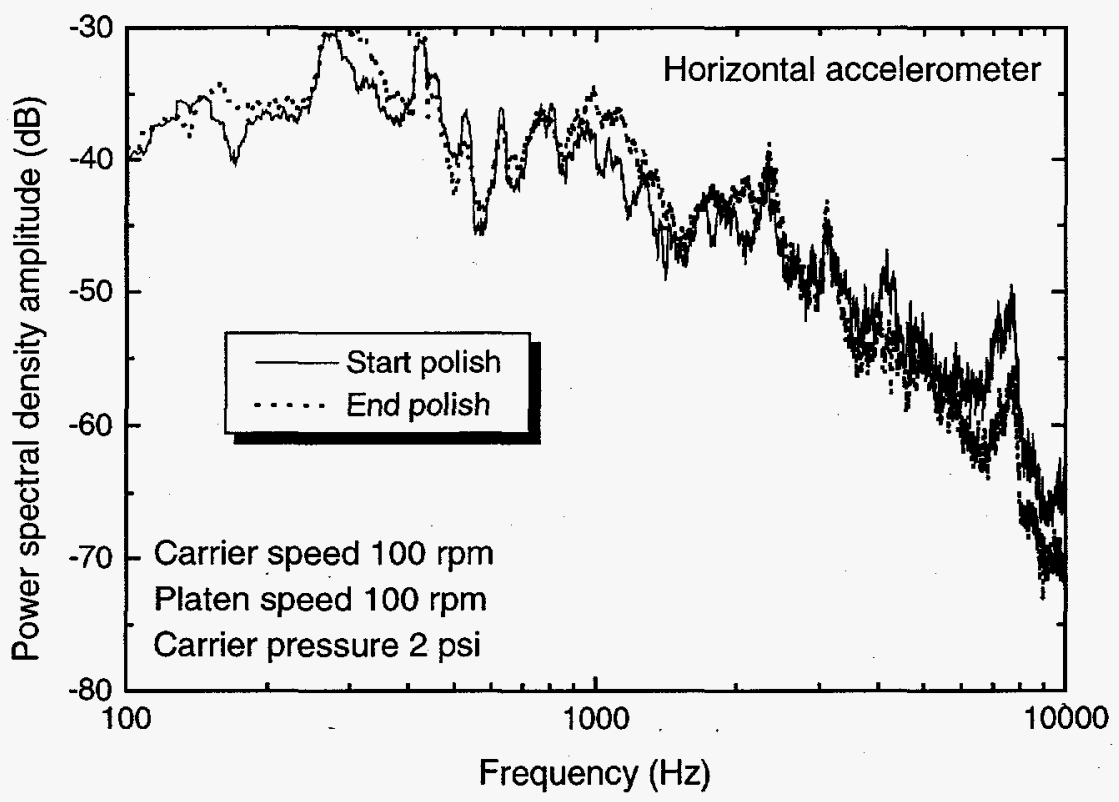

Figure 14. Power spectral density amplitude plot of the horizontal accelerometer vibration amplitude signal monitored during the low-pressure, high-speed planarization process. Shown are the start and end polish times.

To be presented at SPIE Symposium on Microelectronic Manufacturing Technologies- May 19, 1999 


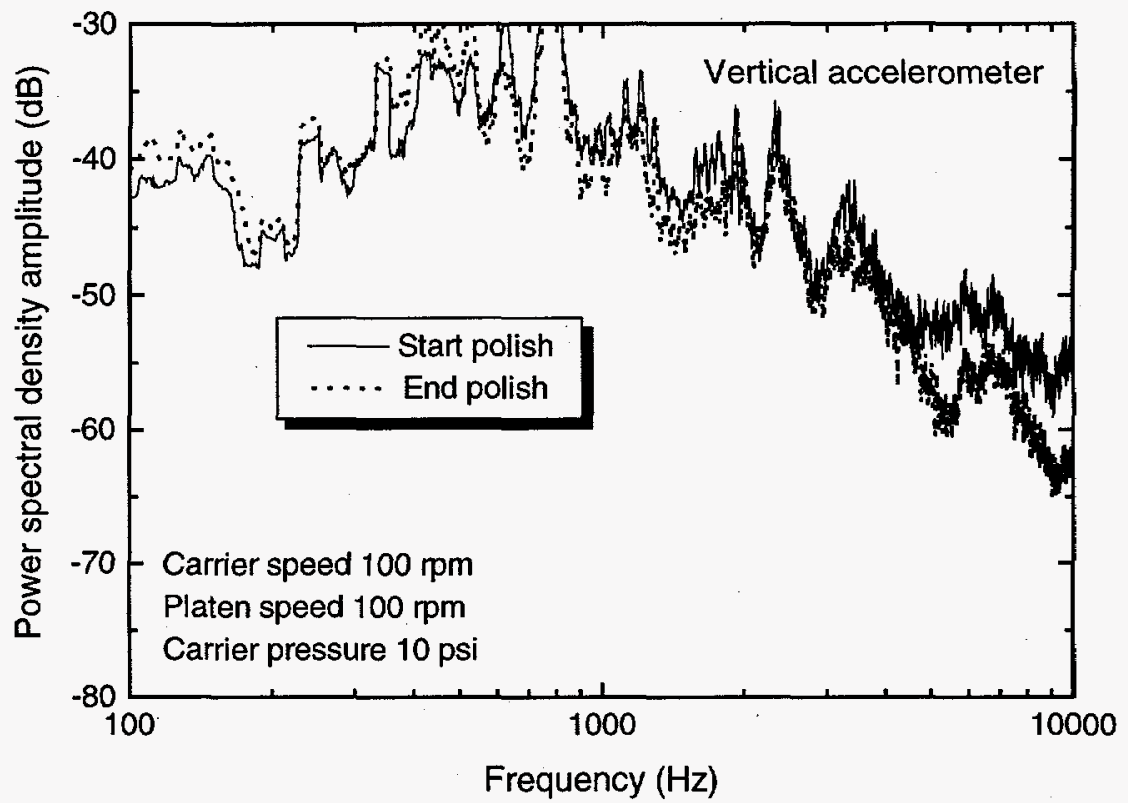

Figure 15. Power spectral density amplitude plot of the vertical accelerometer vibration amplitude signal monitored during the high-pressure, high-speed planarization process. Shown are the start and end polish times.

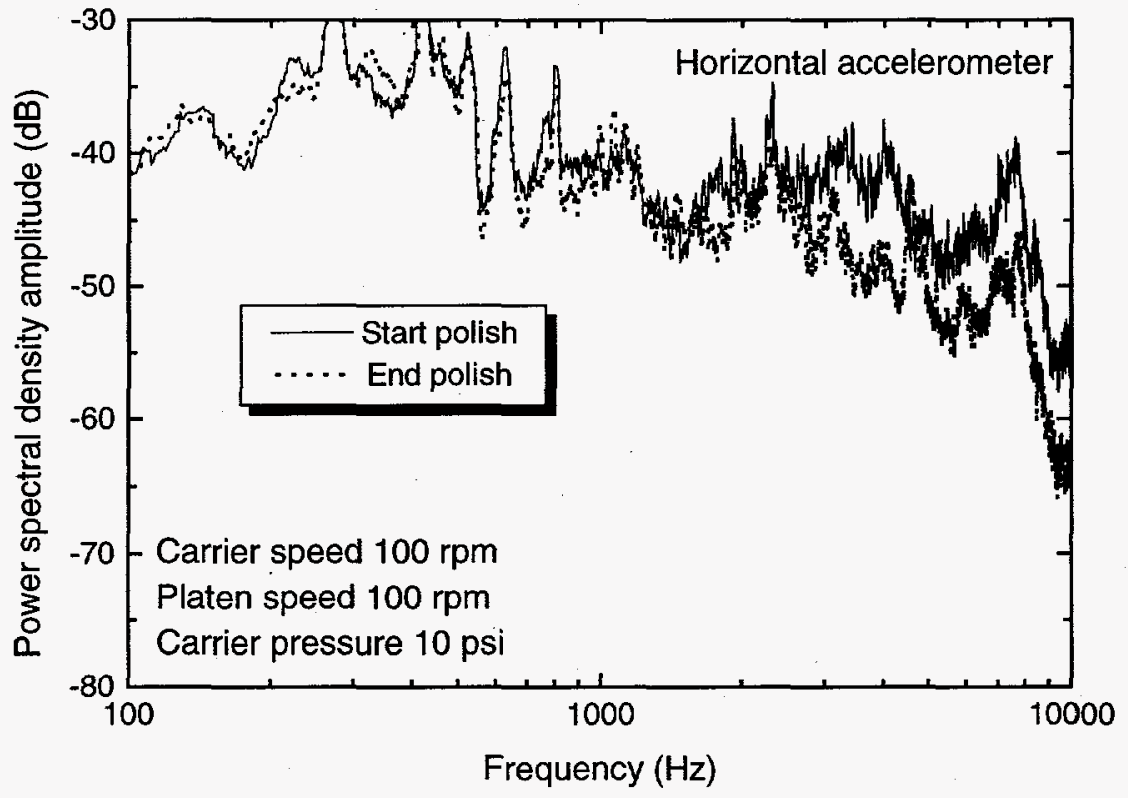

Figure 16. Power spectral density amplitude plot of the horizontal accelerometer vibration amplitude signal monitored during the high-pressure, high-speed planarization process. Shown are the start and end polish times.

As an application of utilizing vibration sensing for detecting planarization end-point, the low-speed high-pressure polish process (Figure 12) was chosen for further analysis. Figure 17 shows the horizontal acceleration signal over a small range of frequencies $(800 \mathrm{~Hz}-900 \mathrm{~Hz})$ for various polish times. These data were averaged for each time and compared to the

To be presented at SPIE Symposium on Microelectronic Manufacturing Technologies- May 19, 1999 
remaining oxide topography step height for this process condition as shown in Figure 18. Based on this simple algorithm, the attenuation in the vibration signal correlates to step height reduction. These results indicate that it is feasible to detect a planarization endpoint for oxide CMP using the vibration sensing method. Development of sophisticated algorithms is required to improve its accuracy as a planarization end-point detector. Improvements to the detection hardware would also ensure its use to a wider application of process parameters.

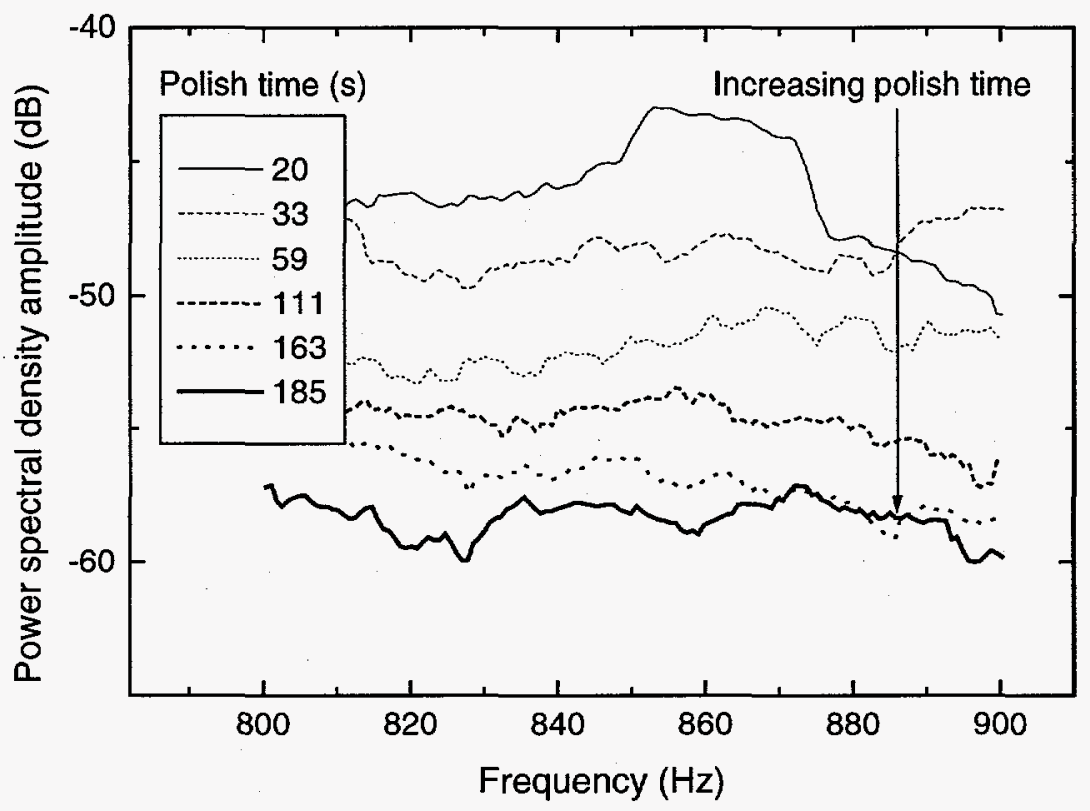

Figure 17. Power spectral density amplitude response for various times acquired during the planarization of a patterned wafer. The signal was from the horizontal accelerometer and the process conditions are given in Fig. 12.

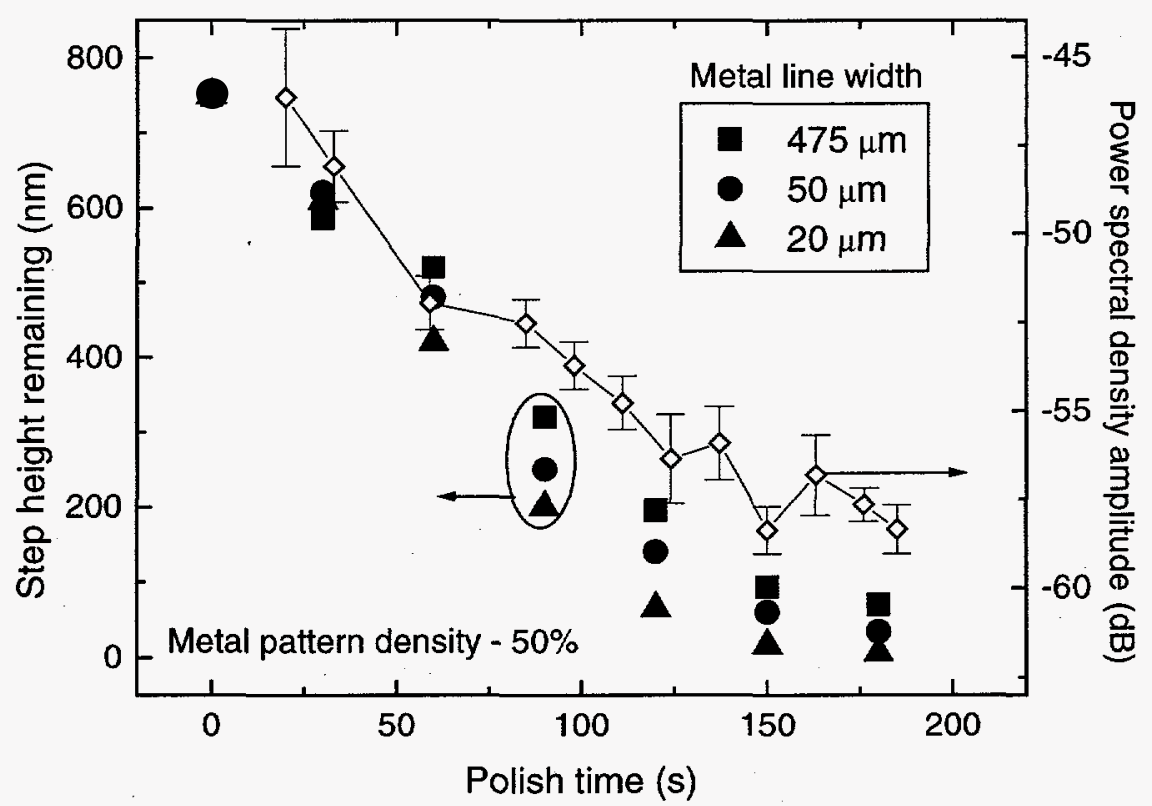

Figure 18. Step height remaining on a patterned wafer with varying metal line widths versus time. Also shown is the horizontal accelerometer amplitude output averaged over the frequency range from $800 \mathrm{~Hz}-900 \mathrm{~Hz}$ versus time.

To be presented at SPIE Symposium on Microelectronic Manufacturing Technologies- May 19, 1999 


\section{CONCLUSIONS}

We have studied the vibrations signals obtained during polish using piezoelectric accelerometers mounted in both the vertical and horizontal directions. Wafers patterned with metal and coated with oxide material were polished at different speeds and pressures. Our results show that the vibration amplitude signal attenuates over time during planarization of oxide material on patterned wafers. The horizontal accelerometer showed more sensitivity to change in amplitude compared to the vertical accelerometer for a given polish condition. The polish rotation speed was an important factor. At low carrier and platen rotation rates, the change in vibration signal over time at fixed frequencies decreased approximately $1 / 2-1$ order of magnitude (over the 2 to $10 \mathrm{psi}$ polish pressure ranges). At high rotation speeds, the vibration signal remained essentially constant indicating that other factors dominated the vibration signal. As an application of utilizing vibration sensing for detecting planarization end-point, the low-speed high-pressure polish process was chosen for further analysis. Based on a simple algorithm that averages the vibration signal over a small range of frequencies, the attenuation in the vibration signal correlated to remaining measured oxide topography step height at particular frequencies. These results suggest that it is feasible to detect planarization end-point for oxide CMP using the vibration sensing method. More detailed analysis is required to determine which frequencies are most sensitive to topography reduction in oxide CMP processes. The development of sophisticated detection hardware and signal processing algorithms may also improve the lower limit of detection for planarization.

\section{ACKNOWLEDGEMENTS}

The authors wish to thank technical assistance from Kim Glidden and Matt Sagartz, and useful discussions throughout the project with Reza Golzarian of Luxtron Corp., Anthony Chu of Endevco Corp., Jeff Witt of Linear Technology Corp., and John Reschovsky of Accumetrics Associates. This work was performed at and supported by Sandia National Laboratories under DOE contract DE-AC04-94AL85000. Sandia National Laboratories is a multi-program laboratory operated by Sandia Corporation for the United States Department of Energy.

\section{REFERENCES}

1. A. Fukuroda, K. Nakamura, and Y. Arimoto, "In situ CMP monitoring technique for multi-layer interconnection", International Electron Devices Meeting Technical Digest, pp. 469-472, 1995.

2. M.-C. Yang, F-Y Shau, C.-S. Huang, C. Yi, and R. Tang, "Comparison of end point detectors for tungsten CMP dual damascene", Proc. $3^{\text {rd }}$ Int. CMP for ULSI Multilevel Interconnection Conf., Feb. 19-20, 1998, p. 216.

3. L. J. Chen, Y.L. Huang, Z. H. Lin, and H. W. Chiou, "Pad thermal image end-pointing for CMP process", Proc. $3^{\text {rd }}$ Int. CMP for ULSI Multilevel Interconnection Conf., Feb. 19-20, 1998, p. 20.

4. W. Yueh, "CMP global endpoint monitor (GEM)", Proc. $3^{\text {rd }}$ Int. CMP for ULSI Multilevel Interconnection Conf., Feb. 19-20, 1998, p. 231.

5. M. Sun, H.-M. Tseng, H. Litvak, and D. Glenn, "In-situ detection of film thickness removal during CMP of oxide and metal layers", Proc. $1^{\text {st }}$ Int. CMP for ULSI Multilevel Interconnection Conf., Feb. 22-23, 1996, p. 256.

6. T. Bibby, and K. Holland, "Endpoint detection for CMP”, J. Elect. Mat., Vol. 27, No. 10, 1998, p. 1073.

7. G. Springer, "Dependence of wafer carrier motor current and polish pad surface temperature signal on CMP consumable conditions and Ti/TiN liner deposition parameters for tungsten CMP endpoint detection", Proc. $4^{\text {th }}$ Int. CMP for ULSI Multilevel Interconnection Conf., Feb. 11-12, 1999, p. 45.

8. J. Tang, D. Dornfield, S. K. Pangrle, and A. Dangca, "In-process detection of micro-scratching during CMP using acoustic emission sensing technology”, J. Elec. Mat., Vol. 27, No. 10, 1998, p. 1099.

9. A. Fukuroda, European patent application EP 0739687 A2, Oct. 10, 1996.

10. C. Yu, U.S. Patent \#5,222,329, June 29, 1993.

11. C. Yu and G. Sandhu, U.S. Patent \#5,240,552, Aug. 31, 1993.

12. I. Salugsugan, U.S. Patent \#5,254,794, Sept. 21, 1993.

13. Y. Ushio, T. Ueda, H. Nakahira, E. Matsukawa, and M. Koyama, "In-situ monitoring of CMP process utilizing 0-order spectrometry", Proc. $4^{\text {th }}$ Int. CMP for ULSI Multilevel Interconnection Conf., Feb. 11-12, 1999, p. 23.

To be presented at SPIE Symposium on Microelectronic Manufacturing Technologies- May 19, 1999 